BALDUINIA, n. 35, p. 01-18, 30-V-2012

\title{
O TIPO DE BUTIA YATAY (MART.) BECC. E DESCRIÇÃO DE UMA ESPÉCIE NOVA DO GENERO'
}

\author{
LEONARDO PAZ DEBLE ${ }^{2}$, JOSÉ NEWTON CARDOSO MARCHIORI ${ }^{3}$, \\ FABIANO DA SILVA ALVES ${ }^{4}$, ANABELA SILVEIRA DE OLIVEIRA DEBLE 5
}

RESUMO

É definido o tipo de Butia yatay (Mart.) Becc. e descrita Butia Noblickii, espécie nova, endêmica do sudeste da província de Corrientes (Argentina). Butia Noblickii pertence ao grupo de espécies de Butia yatay, diferindo, principalmente, por ter flores pistiladas menores $(7-9 \mathrm{~mm} \times 7-8 \mathrm{~mm})$, pelas delgadas espatas papiráceas, e pelo menor número de ráquilas nas inflorescências (56-82).

Palavras-chave: Argentina, Bonpland, Butia Noblickii, Butia yatay, Corrientes, Paso de los Libres, Taxonomia Vegetal.

\section{ABSTRACT}

[The type of Butia yatay (Mart.) Becc. and description of a new species of the same genus]. The type of Butia yatay (Mart.) Becc. is established and a new species of the same genus, named Butia Noblickii is described to southeast of Corrientes province (Argentina). Butia Noblickii belongs to Butia yatay group of species but differs mainly by its smaller pistillate flowers (7-9 $\mathrm{mm} \times 7-8 \mathrm{~mm})$, thinner-papiraceous spathes and a fewer number of rachillae per inflorescence (56-82).

Key words: Argentina, Bonpland, Butia Noblickii, Butia yatay, Corrientes, Paso de los Libres, Plant Taxonomy.

\section{INTRODUÇÃO}

Bem conhecido e valorizado pela população desde o período colonial, o butiá-jataí ou jataí (yatay, em castelhano) é um dos ornamentos mais conspícuos na paisagem da Mesopotâmia argentina, aonde forma extensos palmares.

Apesar de sua notoriedade e importância, a espécie tem suscitado controvérsias na literatura, até mesmo acerca de sua verdadeira distribuição geográfica. No caso do Rio Grande do Sul, por exemplo, com as recentes descrições de Butia Witeckii (Soares \& Longhi, 2011), Butia missionera (Deble et al., 2011) e Butia quaraimana (Deble et al., 2012), a espécie deixou de figurar em sua flora nativa, até prova em contrário.

${ }^{1}$ Recebido em 10-4-2012 e aceito para publicação em 05-5-2012.

2 Dr. Professor do Curso de Ciências da Natureza, UNIPAMPA(Dom Pedrito-RS).deble.biol@gmail.com

${ }^{3}$ Dr. Professor do Departamento de Ciências Florestais, UFSM (Santa Maria - RS).

${ }^{4}$ Dr. Professor do Curso de Ciências Biológicas, URCAMP (Alegrete - RS).

5 Dra. Professora do Curso de Tecnólogo em Gestão Ambiental, URCAMP (Dom Pedrito - RS).
Sob o ponto de vista taxonômico, o esclarecimento de eventuais dúvidas passa, necessariamente, pela definição do tipo de Butia yatay, tema ainda pendente, posto que a espécie foi descrita por Martius (1844: 93) sem a indicação de material coletado, baseada apenas em ilustrações e relatos de Alcide D'Orbigny, um dos mais notáveis viajantes-naturalistas de sua época. O presente trabalho visa a sanar esta importante lacuna e, na seqüência, descrever uma nova espécie para o gênero botânico em questão.

\section{APONTAMENTOS BIBLIOGRÁFICOS}

Deve-se a Martino Dobrizhoffer, padre jesuíta e importante cronista da região do Paraguai no século XVIII, uma das referências mais antigas ao butiá-jataí (yatay). Para o objetivo do presente trabalho, cabe salientar que, mesmo sem validade botânica, o autor atribuiu este nome a duas plantas distintas no primeiro volume de sua obra ${ }^{6}$ : o Yatay, definido como pal-

${ }^{6}$ DOBRIZHOFFER, M. Historia de Abiponibus: Equestri, Bellicosaque Paraquariae Natione. Viena: Typis Josephi Nob. De Kurzbek, 1784. v. 1. p. 409. 
meira pequena; e o Yatay guazu, de folhas longas e maior porte, caráter implícito, aliás, no epíteto de origem guarani (guazu).

$\mathrm{Na}$ literatura botânica propriamente dita, a espécie em estudo foi originalmente descrita como Cocos yatay, por Martius (1844: 93), sem a indicação de material coletado; na seqüência, foi transferida para Calappa, por Kuntze (1891: 982) e, posteriormente, ao gênero Butia, por Beccari (1916: 498).

Na descrição original, Martius remete a identidade da espécie ao texto de Alcide Dessalines D'Orbigny, constante em sua monumental Voyage dans l'Amérique Méridionale, informando que:

"Cette espèce forme des forêts immenses sur tous les terrains sablonneux des provinces de Corrientes et d'Entre-Rios (république Argentine). Il en existe des bois entre Corrientes et Itaty, aux lieux nommés Las Ensenadas. Elle se montre en plus grand nombre à l'est de la province, aux environs de Caacati, et de ce point, en s'avançant au sud, elle constitue ce qu' on appelle le Palmares ou le Yataity guazu des guaranis; dénominations qui équivalent au nom de grande forêt de Yatays. Elle forme en effect des forêts qui couvrent tous le terrains sablonneux, s'étendant parallèlemant au cours de rivières de Santa-Lucia et du Batel, jusqu'aux frontières de la province d'Entre-Rios, c'està-dire sur plus de soixante lieues de longueur. Elle repairêt dans cette province à peu de distance du Parana et y forme des bois épais jusqu'auprès de la Bajada. Ce palmier se trouve donc du $27^{\circ}$ au $32^{\circ}$ degré de latitude sud ou sur cent vingt-cinq lieues en latitude, constituant partout des forêts, où il est pour ainsi dire seul de son espèce"

7 MARTIUS, C.F. P. de. Palmetum orbignianum. Descriptio palmarum in Paraguaria et Bolivia crescentium secundum Alc. De Orbigny exempla, schedulas et icones digessit. In: D'ORBIGNY, A. Voyage dans l'Amérique Meridionale. Paris: P. Bertrand, 1844. p. 94-95.
A leitura atenta do relato de viagem de Alcide D'Orbigny mostra que o francês menciona pela primeira vez o yatay em sua passagem por Yataity, localidade a nordeste da cidade de Corrientes, capital da atual província argentina homônima. Palmares extensos e praticamente intocados de Butia yatay, todavia, somente foram encontrados pelo autor na região de San Roque, antigo vilarejo e atual cidade da mesma província, situada ao sul da capital. Alcide D’Orbigny realizou diversas expedições pela província de Corrientes e, ao retornar para Buenos Aires, em viagem de barco pelo rio Paraná, ele ainda pode observar outros palmares de Butia yatay, inclusive na província de Entre Rios.

Cabe salientar que D'Orbigny não faz qualquer menção à presença do yatay na bacia do Uruguai, apesar de ele descrever uma "imaginária" viagem ${ }^{8}$ a Paysandu (Uruguai), em outra obra $^{9}$. Se o autor tivesse atravessado a província de Entre Rios ${ }^{10}$ de oeste para leste, a partir de La Bajada ${ }^{11}$, ele provavelmente teria conhecido in loco o atual (e bem preservado) "Parque

8 Esta “viagem" é dita imaginária porque D’Orbigny nunca a realizou, verdadeiramente, como se pode concluir ao ler-se o texto integral de suas andanças pela atual $\mathrm{Ar}$ gentina (D'ORBIGNY, A.D. Viaje por América Meridional. Buenos Aires: Emecé, 1998. v. 1. 524 p.).

9 D'ORBIGNY, M. A. Voyage pittoresque dans les deux Amériques. Paris: Imprimerie de Henri Dupuy, 1836. $568 \mathrm{p}$.

10 "Je pouvais, en descendant vers le S., gagner la Bajada, capitale de l'Entre-Rios; et, de là, traverser, jusqu'à Paysandu, cette province, de nom comme de fait, la quatrième des Mésopotamies de l'Amérique que j'avais déjà parcourues; mais, pour en venir là, que de déserts à passer ! que de rios, de bañados, d'esteros à franchir!... Et j'en avais déjà tant vu! Je pris le parti de me rendre dans la republique orientale de l'Uruguay, par un chemin un pleu plus court peut-être, et, dans tous le cas, moins humide (...). Ce trajet très-monotone me conduisit au pueblo de Paysandu, situé sur la rive gauche de l'Uruguay, et le premier lieu habité de la republique orientale" (D'ORBIGNY, 1836. Op. cit., p. 248).

${ }^{11}$ Nome antigo da atual cidade de Paraná, capital da Província de Entre Rios, situada à margem esquerda do rio Paraná. 
Nacional El Palmar"'2, além de extensas áreas com Trithrinax campestris, espécies não citadas no texto do meticuloso viajante para a região. Cabe salientar que a presença de "belas palmeiras" é referida apenas de passagem - e para as margens do rio Uruguai -, citação que sugere tratar-se, em verdade, de Syagrus romanzoffiana ${ }^{13}$. Além disso, ao mencionar "des beaux palmiers", fica implícito que se trata de espécie distinta do yatay, palmeira por ele bem conhecida e repetidas vezes nomeada em seu retorno de Corrientes a Buenos Aires, em viagem de barco pelo rio Paraná.

Apesar de seu aspecto imponente e ampla área de ocorrência na Mesopotâmia argentina, os ditos palmares de "yatay" ainda carecem de uma investigação botânica mais acurada, que envolva, de início, a definição do tipo da espécie, e, na seqüência, o exame das distintas populações ainda existentes nas províncias de Corrientes e Entre Rios (Argentina), bem como em áreas adjacentes.

Foi com base nessa premissa, precisamente, que Deble et al. (2012) descreveram Butia quaraimana para a região do Coatepe, município de Quaraí, contestando antigas referências sobre a distribuição de Butia yatay no Rio Grande do Sul, constantes em Reitz et al. (1983), Marchiori et al. (1995), Mattos (1977), Sobral

${ }^{12}$ Criado em 1966, o Parque Nacional "El Palmar" tem extensão de 8.500 hectares e visa a proteger um setor muito singular da Mesopotâmia argentina, no que diz respeito à flora e à fauna. Situado no centro-leste da província de Entre Rios, a área do parque era anteriormente conhecida como "Palmar Grande" (ERIZE, F.; CANEVARI, M.; CANEVARI, P.; COSTA, G.; RUMBOLL, M. Los parques nacionales de la Argentina y otras de sus áreas naturales. Buenos Aires: El Ateneo, 1993. p. 90-92).

13 "Toujours des rivières et en grand nombre; toujours des plaines, mais pas aussi uniformément plates que celles que je venais de parcourir; et, au lieu de bañados, de cañadas, d'esteros, à n'en plus finir, des terrains secs, garnis de grandes herbes et d'arbustes clairsemés, qui, quoique d'un effet assez agréable, ne pouvaient se comparer, en rien, aux riches aspects des beaux palmiers que j'avais quittés en passant d'une rive à l'autre" (D'ORBIGNY, 1836. Op. cit., p. 248). et al. (2006), Soares \& Witeck Neto (2006), Lorenzi et al. (2004, 2010), Deble et al. (2011), Soares \& Longhi (2011) e Marchiori \& Alves (2011), entre outros.

Para a Mesopotâmia argentina, Crovetto \& Piccinini (1951), entre outros autores, referem Butia yatay (Mart.) Becc. como espécie formadora de palmares ao longo desta vasta região. Destes, o mais conhecido é o "Palmar Grande", localizado entre as cidades de Berduc e Ubajai (província de Entre Rios), transformado no parque nacional anteriormente comentado. Na mesma província, destacam-se, ainda, os palmares de Concórdia e, por sua grande extensão, o situado entre as cidades de Federal e Feliciano. Na província de Corrientes, a espécie compõe, principalmente, duas faixas longas e relativamente estreitas, com desenvolvimento sudoeste-nordeste. A primeira delas começa ao sul de Mburucuyá e alcança as proximidades de General Paz. Mais longa, a faixa leste tem início ao sul de Goya ( $\left.29^{\circ} 40^{\prime} \mathrm{S}\right)$ e se estende até as proximidades de Loreto ( $\left.27^{\circ} 48^{\prime} \mathrm{S}\right)$, aproximadamente. Por sua proximidade com o Rio Grande do Sul, cabe salientar-se, ainda, o palmar que se estende do sudeste de Bonpland a Paso de los Libres (Figura 1), objeto de estudo no presente trabalho. A respeito do mesmo, Marchiori \& Alves (2011) chamam atenção para a ausência de vegetação semelhante no lado brasileiro, à margem esquerda do rio Uruguai, fato atribuído pelos autores à estreita faixa de solos aluviais ali encontrada, com exceção do Pontal do Quaraí, originalmente revestido por parques de inhanduvá.

\section{O TIPO DE BUTIA YATAY}

Ao descrever Cocos yatay, Martius (1844: 93) citou no protólogo a ilustração da prancha I, figura $1 \mathrm{e}$ as ilustrações da prancha XXX, figura $\mathrm{C}$ (que em verdade é a $\mathrm{B}$ ), sem qualquer menção, todavia, a material coletado (Figuras 2 e 3, p. 9 e 10).

Drude (1881: 421-422) menciona a existência de extensos bosques de Cocos yatay em campos arenosos do Brasil extratropical (Silvas ex- 


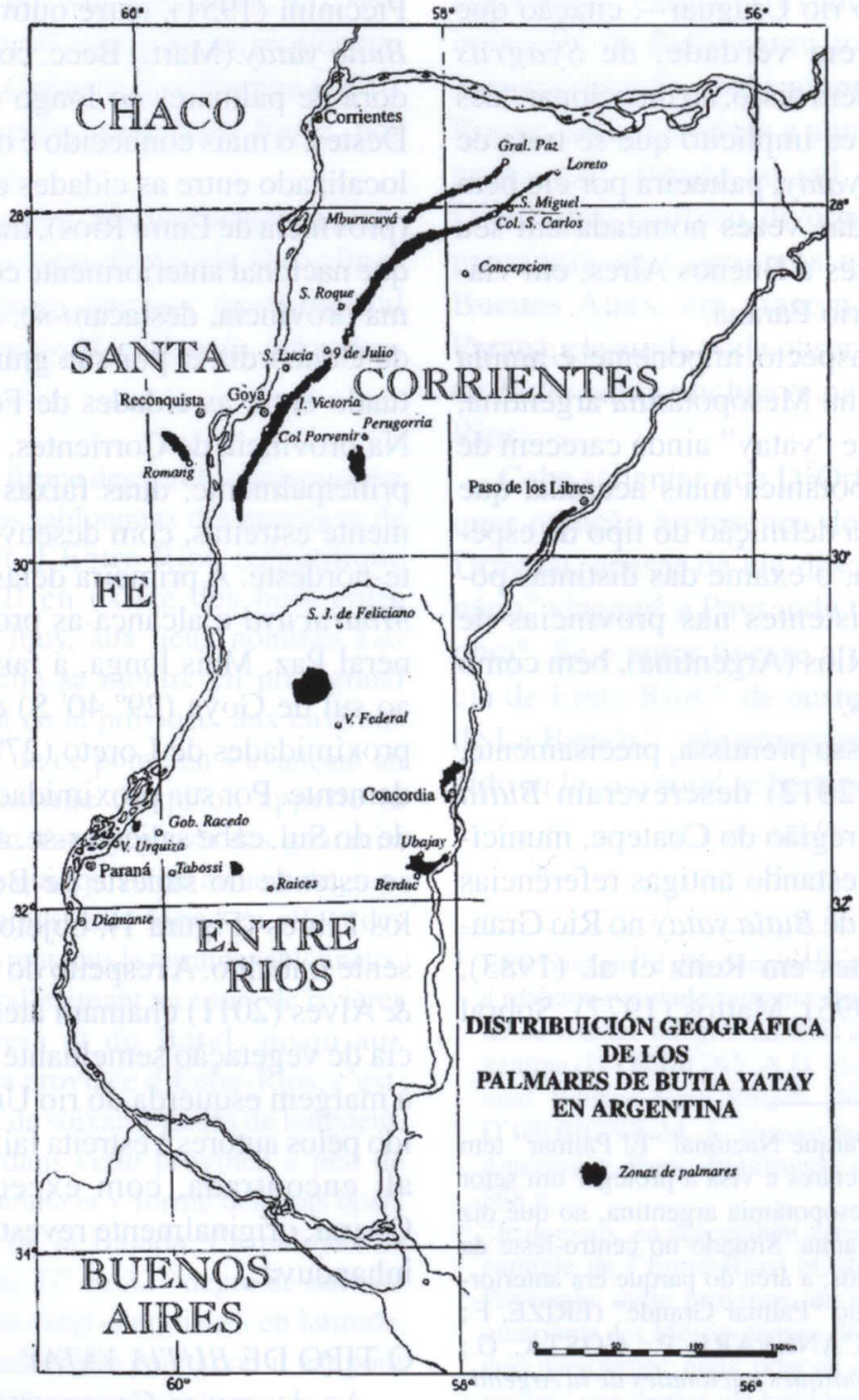

FIGURA 1 - Distribuição geográfica dos palmares de Butia yatay na Argentina, segundo Crovetto \& Piccinini (1951). 
tensas (...) in Brasiliae extratropicae), sugerindo a possibilidade da ocorrência da espécie também na parte tropical do território brasileiro (... etiam Tropicae?); o mesmo autor também refere sua distribuição na Argentina, em Corrientes e Entre Rios, em cursos secos dos rios Santa Lucia, Batel e, conforme D'Orbigny, também no rio Paraná (in prov. Corrientes et Entre Rios, secus cursus fluv. S. Lucia et Batel, etiam ad flum. Parana (Orbigny)). O autor citou um exemplar coletado por Lorentz em Concordia (Entre Rios, Argentina) e outro por Sellow no Brasil, este último sem local especificado (et pr. Concordia (Lorentz!); in Brasilia sine loco speciali Sello! $)^{14}$, resultando essas duas coletas nas primeiras menções de exsicatas atribuídas à referida espécie.

$\mathrm{O}$ texto transcrito a seguir demonstra que Drude não estava de acordo com a descrição e iconografia de Martius na obra príncipes, motivo da necessidade da emenda proposta na Flora Brasiliensis para a espécie em questão.

"ex fragmentis Orbgnianis facta nune speciminibus optimis emendata et iconibus illustrata. In tabula Palmeti Orbigniani $30 \mathrm{f}$. B. spadicis ramus delineatus est, qualis nunquan invenitum, florum portio non naturalis; putamen non in verticem rotundatum sed acutum; est drupam carnosam esse jam ex usu ab cl. Orbigny citato proditi; segmenta omnino plura quam 100 saepe adsunt, non usque 50. -Ex tali comparatione speciminu bene collectorum cum descriptionibus incompletis Palmeti Orbigniani discerneri licet quantus siti valor in specierum characteribus ibi ex not Orbignianis commemoratis quare inulti emendandi apparent" ${ }^{15}$.

Cabe salientar que a emenda proposta por Drude deixa dúvidas se o material descrito corresponde a Cocos yatay, conforme a propos-

\footnotetext{
${ }^{14}$ Notar a importância do sinal de exclamação "!" junto aos nomes de Lorentz e Sellow, indicativos de que Drude analisou as exsicatas coletadas por esses naturalistas.

${ }^{15}$ DRUDE, C. G. O. Flora Brasiliensis v. 3, parte II, p. 421-422. 1881.
}

ta seminal de Martius, baseada nos relatos e ilustrações de D’Orbigny, ou se Drude fundamentou-se em material de diferentes espécies para compor sua descrição botânica.

Na descrição feita por Drude (1881: 421), o autor mencionou caules de 4-5 $\mathrm{m}$ de altura e folhas de 2-3 metros, com 50-60 pares de folíolos. As dimensões de caule são modestas, comparadas ao protólogo de Martius e à ilustração de D’Orbigny (Figura 2, p. 9) ${ }^{16}$. Com relação ao número de pares de folíolos, Drude ressaltou que Martius havia exagerado ao citar mais de 100 pares, na descrição original de Cocos yatay ${ }^{17}$.

As flores masculinas, conforme a descrição da página 421 da Flora Brasiliensis, variam de 4 a $8 \mathrm{~mm}$, e as femininas de $12-15 \mathrm{~mm}$ de comprimento e 8-10 mm de diâmetro; os frutos, por sua vez, atingem $3 \mathrm{~cm}$ de comprimento e 2.5-3 $\mathrm{cm}$ de diâmetro. As medidas citadas são conflitantes, posto que as flores masculinas mostram-se relativamente pequenas, como em espécies do grupo de Butia odorata (Barb. Rodr.) Noblick $^{18}$, ao passo que as flores femininas são relativamente grandes, à semelhança das encontradas nas espécies do complexo Butia yatay. A forma e as dimensões do fruto assemelham-se a Butia odorata; no entanto, o endocarpo com "2cm lg et $13 \mathrm{~mm}$ " apresenta medidas típicas das espécies do grupo de Butia yatay.

Uma análise detalhada das duas belas pranchas ilustradas na Flora Brasiliensis sob o nome

${ }^{16}$ A prancha I (Martius, 1884, Op. cit.), elaborada por D'Orbigny, mostra três espécies de palmeiras, cada uma em seu ambiente típico: Cocos yatay, em uma elevação do terreno, e Cocos australis (= Syagrus romanzoffiana (Cham.) Glassman) e Copernicia cerifera $(=C$. alba, em verdade), em terreno relativamente baixo. As espécies foram representadas em proporção e tendo por base a figura de uma pessoa, exatamente ao lado da ilustração de Cocos yatay, o que permite estimar a planta em questão em oito metros de altura, pelo menos.

17 “.... ab cl. Orbigny citato proditi; segmenta omnino plura quam 100 saepe adsunt, non usque 50" (DRUDE, 1881. Op. cit., p. 422.)

${ }^{18}$ Butia odorata foi descrito 10 anos após a publicação da Flora Brasiliensis, sob o binômio de Cocos odorata (BARBOSA RODRIGUES, J. Plantas novas Cult. Jard. Bot. Rio-de-Janeiro I, t. IV, A et V. 1891). 
de Cocos yatay (Figuras 4 e 5, p. 11 e 12) evidencia, de maneira definitiva, que Drude baseou a sua descrição de Cocos yatay em duas espécies, pelo menos.

A citada prancha 94, da Flora Brasiliensis (Figura 4, p. 11), mostra um folíolo da parte mediana da folha, com proporção largura/comprimento de $1 / 60$, o que não corresponde a nenhuma espécie conhecida do complexo Butia yatay. Nas folhas de Butia yatay e Butia missionera Deble \& Marchiori, a proporção largura/comprimento varia de $1 / 20$ a $1 / 30$; em Butia quaraimana Deble \& Marchiori, que apresenta as folhas mais estreitas desse complexo, a proporção máxima é de $1 / 40$. Na mesma prancha, a flor feminina é pequena e ovada, lembrando, por sua forma, as flores de Butia odorata.

$\mathrm{Na}$ citada prancha 95, da Flora Brasiliensis (Figura 5, p. 12), são ilustrados três frutos maduros, um deles em corte longitudinal. $\mathrm{O}$ fruto estampado à esquerda, dado sua forma quase globular, assemelha-se aos de Butia odorata, ao passo que os outros dois são, provavelmente, de Butia missionera.

Com base no acima exposto, evidencia-se a fragilidade da emenda proposta por Drude e seus questionamentos em relação à descrição original de Martius, derivados da falta de análise de espécimes das localidades em que D’Orbigny e Martius basearam as suas ilustrações e descrição botânica, respectivamente.

O reconhecimento das exsicatas analisadas por Drude como tipo não está de acordo com o ICBN, tendo em vista que esse material não foi mencionado na obra príncipes; além desse fato, a descrição baseada neste material entra em confronto com o protólogo elaborado por Martius (1844: 93).

Ao transferir Cocos yatay para Calappa, Kuntze (1891: 982) não mencionou material examinado. Beccari (1916: 498-501), ao alocar a espécie em questão para o binômio atualmente váli- do, relatou que sua descrição baseou-se em um belíssimo exemplar, que há muitos anos florescia e frutificava no Jardim Botânico de Nápoles.

A ilustração de Cocos yatay, mencionada na obra príncipes de Martius (1844), mostra um indivíduo de oito metros de altura, pelo menos, com tronco tortuoso, mais ou menos cilíndrico em toda a sua extensão, e cerca de 25 folhas contemporâneas (Figura 2, p. 9). São ilustradas na prancha $\mathrm{XXX}$, figura $\mathrm{B}$, da mesma obra: as folhas (1), uma ráquila da inflorescência (2), o fruto alongado e bicudo (4), e o endocarpo ovado-elíptico, com base (representada como se fosse o ápice) prolongada em bico triangular (5) (Figura 3, p. 10).

As ilustrações das pranchas I e XXX correspondem, em muitos aspectos, a exemplares de Butia yatay do nordeste da Argentina. Resta salientar que a prancha XXX merece ser considerada como tipo da espécie e está registrada no Herbário de Paris sob o número P02147677. Na falta de material original representado em herbário, propõe-se, no presente artigo, um epitypus para Butia yatay, proveniente de localidade típica.

Butia yatay (Mart.) Becc. L'Agricoltura Coloniale v. 10, n. 10-11, p. 498. 1916. Cocos yatay Mart. Voyage dans 1'Amérique Méridionale 93 , t. 1, f. 1, t. 30B. 1844. Calappa yatay (Mart.) O. Kuntze, Ver. Gen. Pl. 2, p.982. 1891. Syagrus yatay (Mart.) Glassman, Fieldiana, Botany 32, n. 10, p. 157. 1970. Typus: Prancha 1 (figura 1) e Prancha XXX (figura B: 1-5). Epytypus (hic locus designatus): ARGENTINA. Corrientes: Goya, Paraje Mercedes Cossio, "estípite de 30-35 cm de diametro, cubierto por los restos peciolares, 4 metros de altura, más o menos, pecíolo y vaina $80 \mathrm{~cm}$ largo, lámina de $1.60 \mathrm{~cm}$ de largo, glauca, espata $1.20 \mathrm{~m}$ de largo, parda-glabra. 21-XI-1970, M.M. Arbo \& V. Maruñak 553 (CTES 43769 a-e!). 


\section{DESCRIÇÃO DE UMA NOVA ESPÉCIE}

Butia Noblickii Deble, Marchiori, F. S. Alves \& A. S. Oliveira sp. nov.

A Butiae quaraimanae cui maxime proxima inflorescentiae rachillae usque ad 82 (vs. 108152), flores feminei 7-9 mm longus et 7-8 $\mathrm{mm}$ latus (vs. $11-13 \mathrm{~mm}$ longus, 6-8 mm latus), late ovato-turbinatus (vs. ovato-turbinatus) et spadix lignoso-papiraceis (vs. lignosis), differt. A Butiae yatay primu aspectu sed palmae usque 8 $m$ altae ( $v s$. usque $16 \mathrm{~m}$ altae), caudex brevioribus 2-6 m altus (vs. 6-14 m altus), foliis cum foliolae mediae 55-65 cm longae, 1.2-1.8 $\mathrm{cm}$ latae ( $v \mathrm{~s}$. $55-80 \mathrm{~cm}$ longae, $2-3 \mathrm{~cm}$ latae), endocarpio elliptico, 18-24 mm longo, 10-14 $\mathrm{mm}$ lato (vs. ovato-elliptico $24-28 \mathrm{~mm}$ longo, $14-18 \mathrm{~mm}$ (ato), productus bene differt.

TYPUS: ARGENTINA. Corrientes, Paso de los Libres, "en palmar de Buttia yatay, 3 a 5 m de altura, flores amarillas", 1-XI-1973, A. Schinini 7828 (Holotypus CTES!).

Palmeira solitária com 3-8 $\mathrm{m}$ de altura. Estipe de 2-6 $\mathrm{m}$ de altura e $25-35 \mathrm{~cm}$ de diâmetro, com remanescentes das bainhas foliares na parte distal e cicatrizes dispostas em torno do estipe na parte proximal. Folhas contemporâneas 1424 , medindo $180-270 \mathrm{~cm}$ de comprimento, ereto-arqueadas ou arqueadas, concolores ou suavemente discolores, verde acinzentadas em ambas as faces. Pecíolo com 70-80 cm de comprimento e $2-2.5 \mathrm{~cm}$ de largura, plano na face adaxial e angulado na abaxial; margens providas de espinhos e fibras achatadas; espinhos com $1.5-5 \mathrm{~cm}$ de comprimento, agudos ou obtusos, os proximais ascendentes, enquanto os distais eretos ou retorsos. Bainha com até $45 \mathrm{~cm}$ de comprimento e $10-18 \mathrm{~cm}$ de largura. Raque das folhas com 100-200 cm de comprimento e 1$1.5 \mathrm{~cm}$ de largura, contendo 54-62 pares de folíolos, ascendentes e formando um $\mathrm{V}$ com os folíolos da outro lado da raque. Folíolos medianos de 55-65 cm de comprimento e $1.2-1.8 \mathrm{~cm}$ de largura, cinza-azulados, com nervura media- na evidente em ambas as faces, angulosa, de 1.4$1.5 \mathrm{~mm}$ de largura. Bráctea peduncular oblanceolada de 70-110 $\mathrm{cm}$ de comprimento; parte expandida com $50-65 \mathrm{~cm}$ de comprimento, 5-7 $\mathrm{cm}$ de largura e $1.8-2 \mathrm{~mm}$ de espessura, terminada em um bico de 1-2 cm, glabra e suavemente estriada longitudinalmente em ambas as faces. Prófilo marrom, fibroso, medindo $35-$ $40 \mathrm{~cm}$ de comprimento, oculto pelo pecíolo e bainha das folhas. Pedúnculo da inflorescência branco-creme, delicadamente estriado, suavemente anguloso ou terete, medindo $30-45 \mathrm{~cm}$ de comprimento por $1.5-2.2 \mathrm{~cm}$ de diâmetro. Raque da inflorescência branco-creme, angulosa, $40-55 \mathrm{~cm}$ de comprimento, $1-1.5 \mathrm{~cm}$ de largura, com 56-82 raquilas. Raquilas flexuosas, branco-creme ou creme-esverdeadas; as basais com 20-28 cm de comprimento; as medianas com 13-16 cm de comprimento; as apicais com $8-12 \mathrm{~cm}$ de comprimento. Flores estaminadas branco-creme; as basais pedunculadas, pedúnculos de 6-12 $\mathrm{mm}$; as superiores sésseis ou quase sésseis; sépalas lanceoladas ou elípticolanceoladas, 2-3 mm de comprimento, 1-1.4 mm de largura; pétalas elíptico-lanceoladas ou oblongo-lanceoladas, 4.5-6 mm de comprimento, $1.5-2 \mathrm{~mm}$ de largura. Flores pistiladas branco-creme ou creme esverdeadas, largamente ovado-turbinadas, angulosas ou suavemente angulosas, 7-9 $\mathrm{mm}$ de comprimento, 7-8 $\mathrm{mm}$ de largura, apiculadas no ápice, base alargada. Fruto amarelo ou amarelo-alaranjado, largamente ovado turbinado, bicudo, com $3.5-4 \mathrm{~cm}$ de comprimento, $2.5-3 \mathrm{~cm}$ de diâmetro, coberto pelas escamas do perianto no terço proximal; mesocarpo pouco fibroso, suculento; endocarpo ósseo, elíptico, agudo em ambas as extremidades 18-24 mm de comprimento, $10-14 \mathrm{~mm}$ de diâmetro, suavemente anguloso, com 2 sementes (Figuras 6-8, p. 13-15).

Distribuição \& habitat: Butia Noblickii ocorre no sudeste da província de Corrientes (Argentina), em solos arenosos e dunas ao longo do rio Uruguai. Encontram-se indivíduos isolados e pequenos grupos desde as proximidades 
de Yapeyú até Bonpland. O palmar, todavia, mostra-se mais conspícuo nos arredores da cidade de Paso de los Libres, ao sul do Arroio yatay, compondo faixa mais ou menos contínua até o sudeste da cidade de Bonpland (Figura 9, p. 16).

Etimologia: a espécie é dedicada a Larry Noblick, especialista de Arecaceae que reconheceu o material, em etiquetas de herbário, como provavelmente nova.

Comentários: Butia Noblickii pertence ao complexo de B. yatay e separa-se facilmente das demais espécies do grupo pela forma e dimensões das flores pistiladas, bem como pela bráctea peduncular lenhoso-papirácea, de 1.8-2 $\mathrm{mm}$ de espessura. Pelo tamanho do estipe, forma da copa e dimensões das folhas, Butia Noblickii é afim a B. quaraimana Deble \& Marchiori (2012: 12), da qual difere pela espata lenhosopapirácea, pelo menor número de raquilas na inflorescência e pelas flores pistiladas menores, com formato largamente ovado-turbinado. De Butia yatay, binômio em que a espécie estava identificada em etiquetas de herbário, separase pela menor altura dos indivíduos (3-8 $\mathrm{m} v s$. até $16 \mathrm{~m}$ de altura), pelo estipe curto (2-6 $\mathrm{m} v \mathrm{~s}$. 6-14 m), pelo menor tamanho dos folíolos na parte mediana $(55-65 \mathrm{~cm} \times 1.2-1.8 \mathrm{~cm} v$ s. $55-80$ $\mathrm{cm} \times 2-3 \mathrm{~cm}$ ), e pela forma elíptica do endocarpo (vs. ovado-elíptica), que mede $18-24 \mathrm{~mm} \times 10$ $14 \mathrm{~mm}$ (vs. 24-28 mm x 14-18 mm). A Tabela 1 relaciona as principais diferenças entre $B$. Noblickii e espécies afins.

Conservação: Butia Noblickii é conhecido apenas para o sudeste da província de Corrientes, em área inferior a $500 \mathrm{Km}^{2}$, compondo uma faixa longa e relativamente estreita, paralela ao rio Uruguai, vinculada a solos arenosos. A população é afetada pela atividade agrícola (cultivo de melancias, entre outros produtos) e criação de gado, mostrando sinais de declínio gradativo. De acordo com os critérios da IUCN (2010), Butia Noblickii deve ser considerada em perigo: EN B1, 2a, b(ii,iii), C.
Paratypi:ARGENTINA. Corrientes, Paso de los Libres, Laguna Mansa, "albardón-arena N.V. yatay", 2-XI-1973, A. G. Schulz 18543 (CTES!); Vicinity of the Rio Uruguay, Parque Manicira, "ca. $150 \mathrm{~m}$ from the Puente Uruguay, ca. $38 \mathrm{~m}$, 29 44.015S, 57 06.416W. 2-III-2004, L. Noblick 5406, A. Schinini \& R. Vanni (CTES! FTG); cerca de $1500 \mathrm{~m}$ ao sul da ponte internacional, Paso de los Libres (Corrientes, Argentina), 10II-2011, L. P. Deble, A. S. de Oliveira-Deble \& J. N. C. Marchiori 13999 (HDCF).

Nota histórica: Um dos registros literários mais antigos sobre o palmar de Butia Noblickii encontra-se no livro de viagens do médico e naturalista alemão Robert Avé-Lallemant ${ }^{19}$, que percorreu o Rio Grande do Sul em 1858, movido por uma "necessidade interior, um dever sagrado" de visitar Aimé Bonpland. O célebre botânico e companheiro de viagens de Alexander von Humboldt encontrava-se muito doente ${ }^{20}$ naquela época, vivendo em sua "Estância de Santana", em território argentino (província de Corrientes) ${ }^{21}$. Após a travessia do rio Uruguai, de Uruguaiana para Restauración ${ }^{22}$, o viajante alemão seguiu a cavalo no dia 17 de abril de 1858 para a referida estância de "Dom Amado", nome pelo qual era por todos conhecido e muito estimado o velho botânico fran-

${ }^{19}$ AVÉ-LALLEMANT, R. Viagem pelo sul do Brasil no ano de 1858. Rio de Janeiro: Instituto Nacional do Livro, $1953.398 \mathrm{p}$.

${ }^{20}$ Aimé Bonpland faleceu em 4-05-1858, passados apenas 17 dias da visita de Avé-Lallemant. Outros autores referem 11-05-1858 como data de falecimento.

${ }^{21}$ Sobre este objetivo, Avé-Lallemant comentou que "poucos dos que tiveram a felicidade de apertar as mãos do grande Alexandre von Humboldt em Berlim foram até ao Uruguai visitar o velho Bonpland. (...). A Estância de Santana, na margem esquerda do Uruguai, era o ponto sudoeste de toda a minha viagem, o objetivo de minha peregrinação. E quem sabe não fora eu o último mensageiro da raça européia, da ciência européia, que avançara muitas milhas para, em si e em nome da ciência, levar ao velho Bonpland estima, amor e cordial amizade" (AVÉ-LALLEMANT, 1953. Op. cit., p. 287).

${ }^{22}$ Antigo nome de Paso de los Libres, cidade situada frente a Uruguaiana, na margem direita do rio Uruguai. 


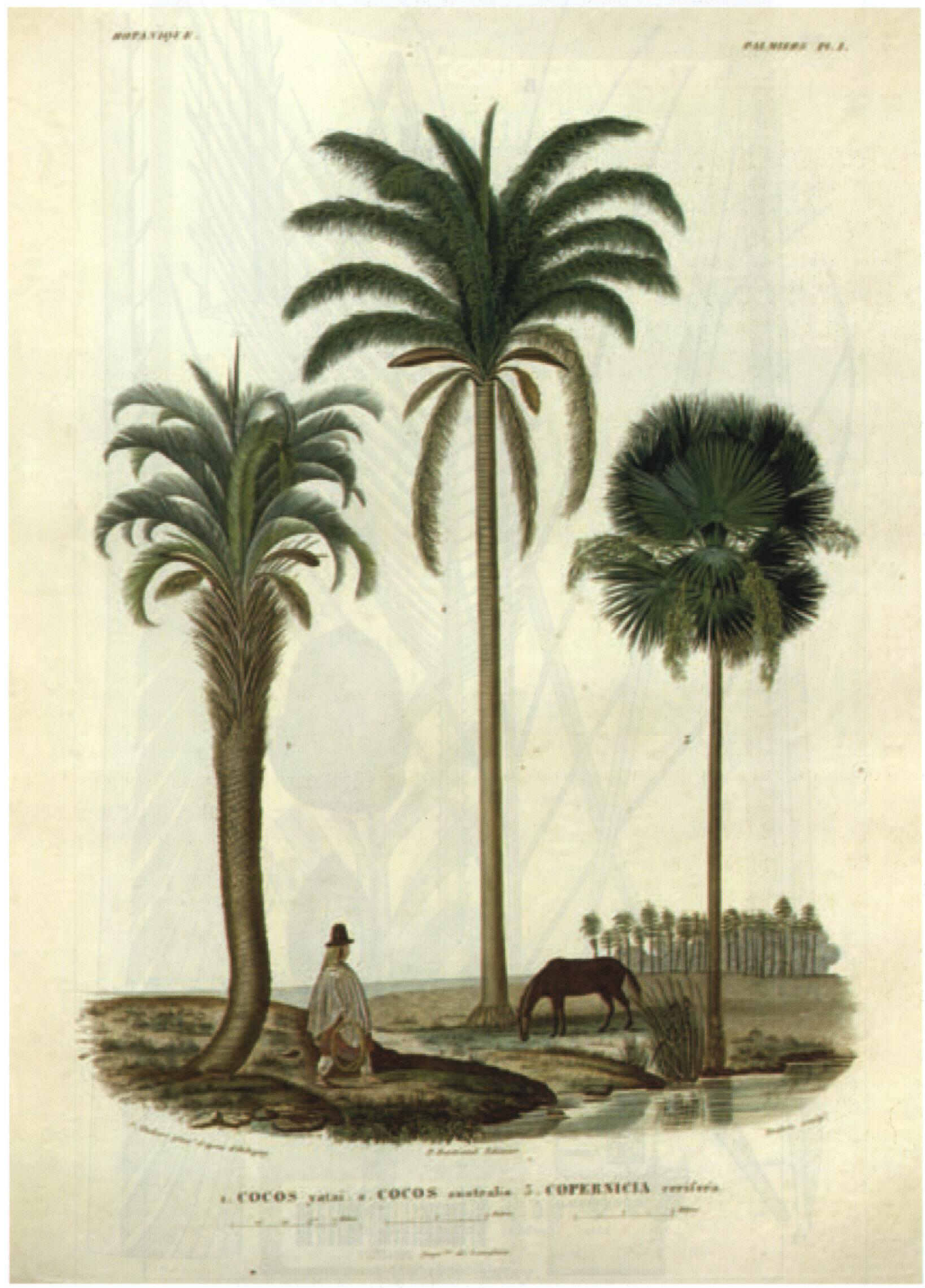

FIGURA 2 - Butia yatay, Syagrus romanzoffiana e Copernicia alba (Cocos yatay, Cocos australis e Copernicia cerifera, respectivamente, segundo Martius, 1844: prancha I). 


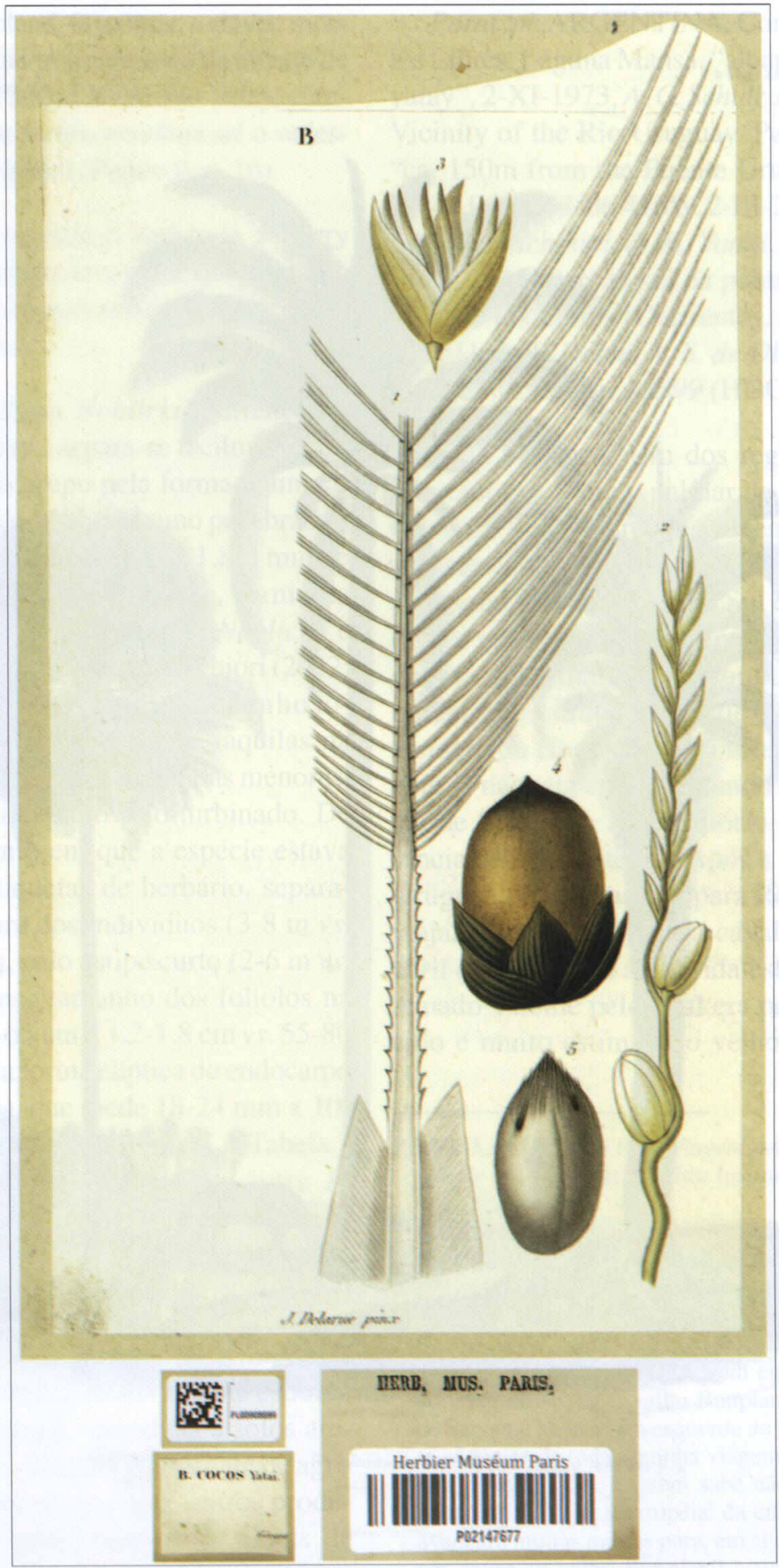

FIGURA 3 - Butia yatay (Cocos yatay, segundo Martius, 1844: prancha XXX B); as etiquetas, coladas originalmente à folha, são apresentadas abaixo da ilustração. 


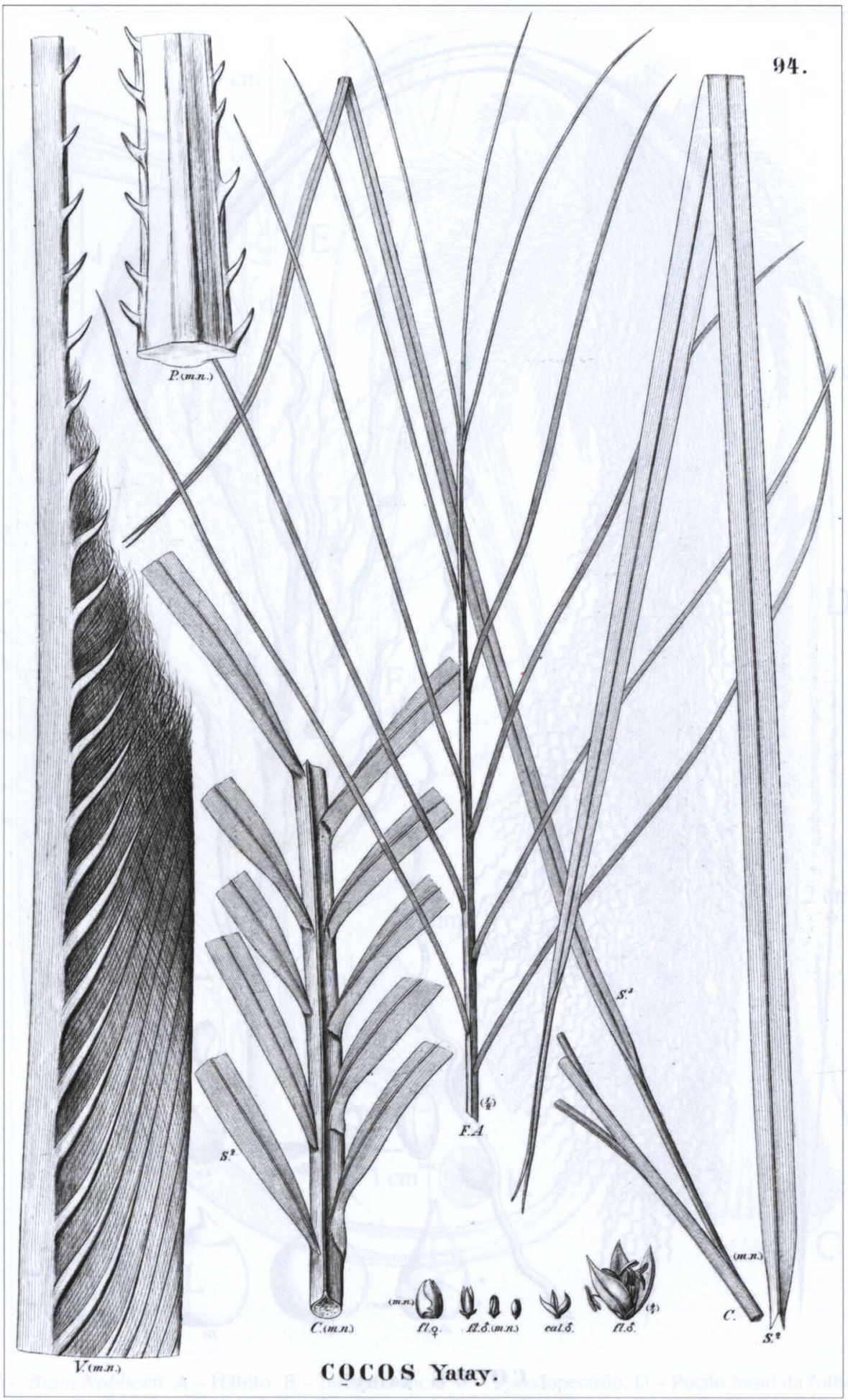

FIGURA 4 - Butia yatay (Cocos yatay, segundo Drude, 1881: prancha 94). 


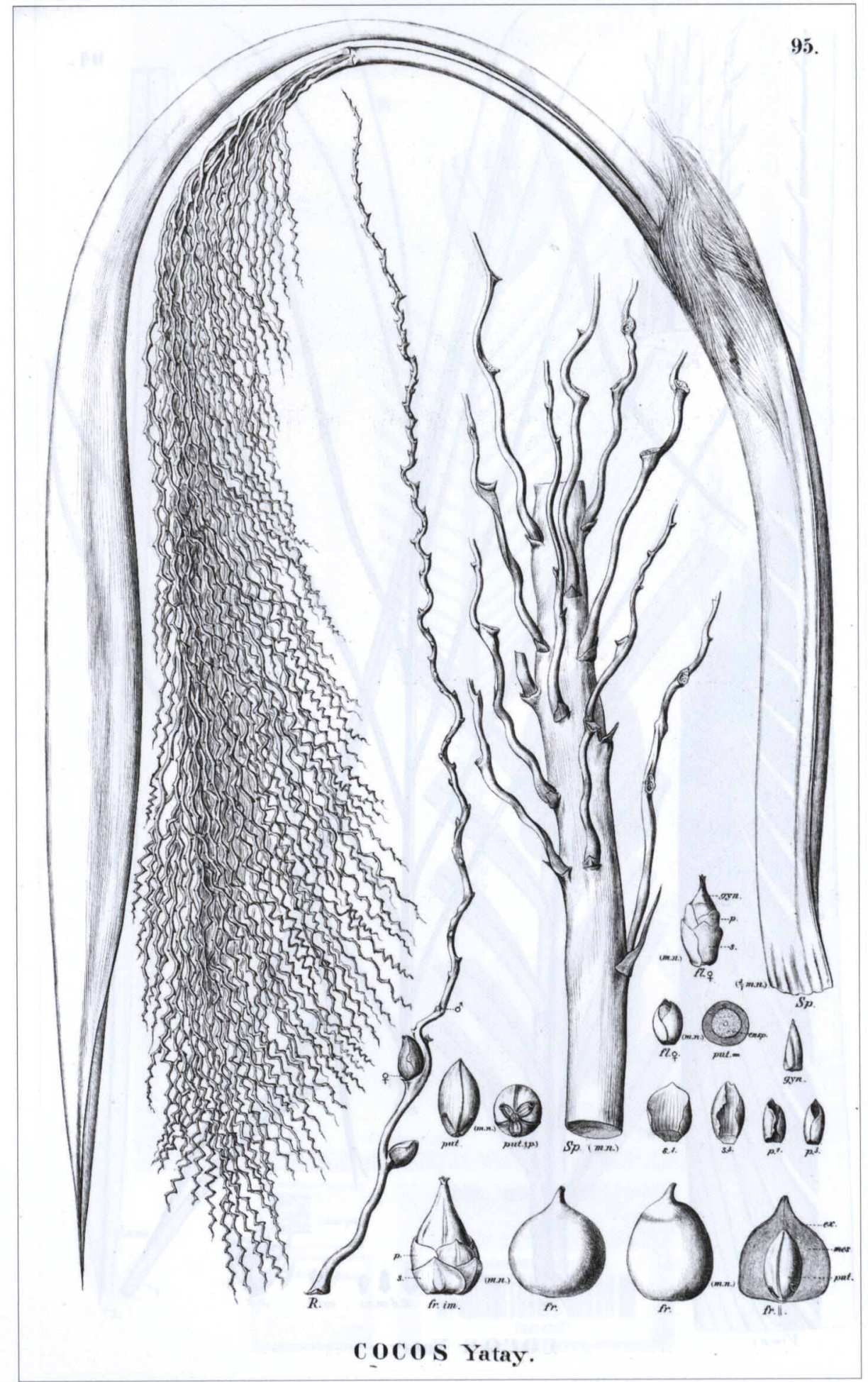

FIGURA 5 - Butia yatay (Cocos yatay, segundo Drude, 1881: prancha 95). 


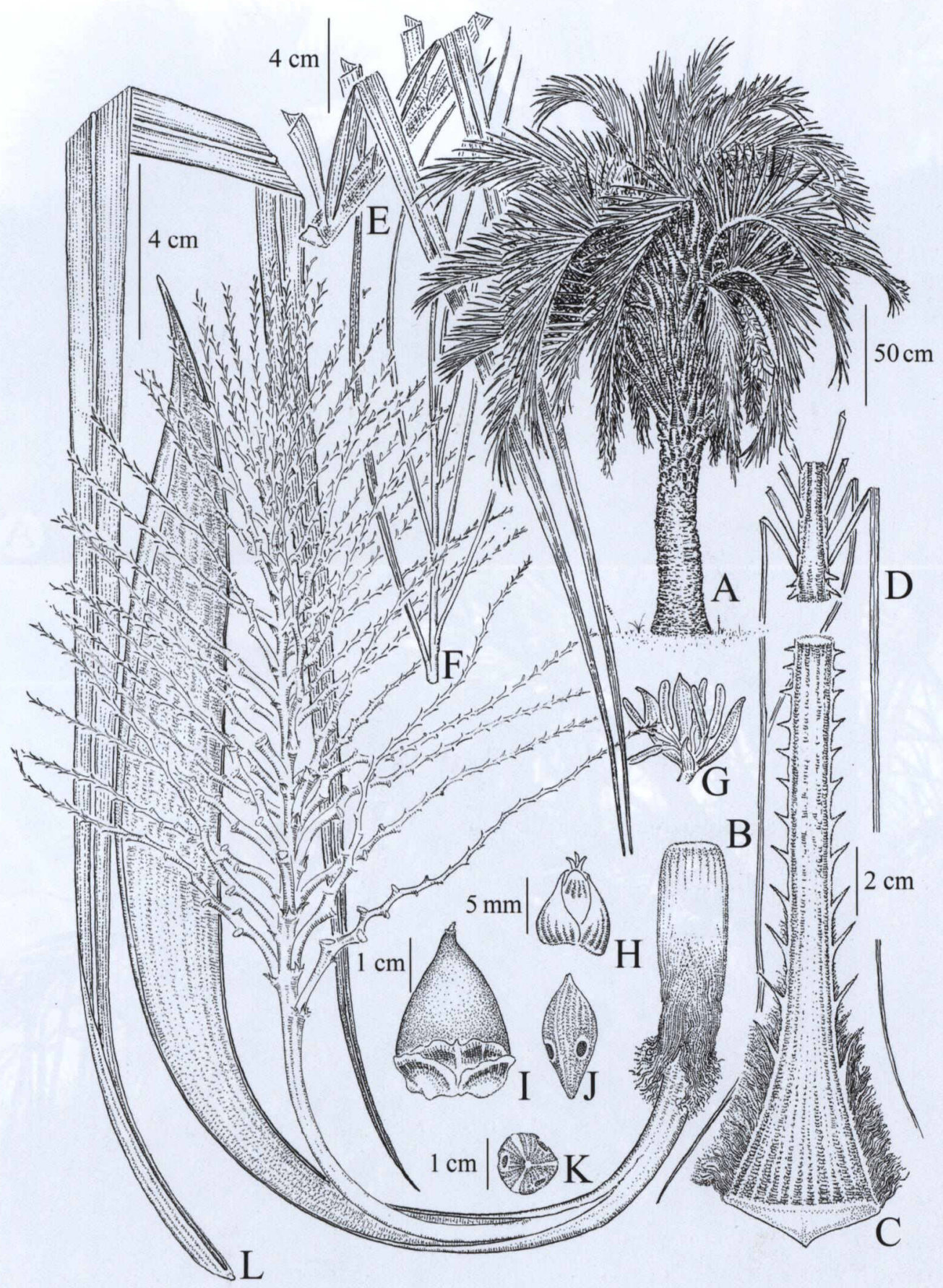

FIGURA 6 - Butia Noblickii. A - Hábito. B - Inflorescência. C - Pseudopecíolo. D - Poção basal da folha. E - Porção mediana da folha. F - Porção apical da folha. G - Flor estaminada. H - Flor pistilada. I - Fruto maduro e perianto. J - Endocarpo. K - Encodarpo, visão dos poros. L - Folíolos da parte mediana da folha. (A, I-K, L. P. Deble, A.S. de Oliveira-Deble \& J.N.C. Marchiori 13999; B-H, A. Schinini 7828). 


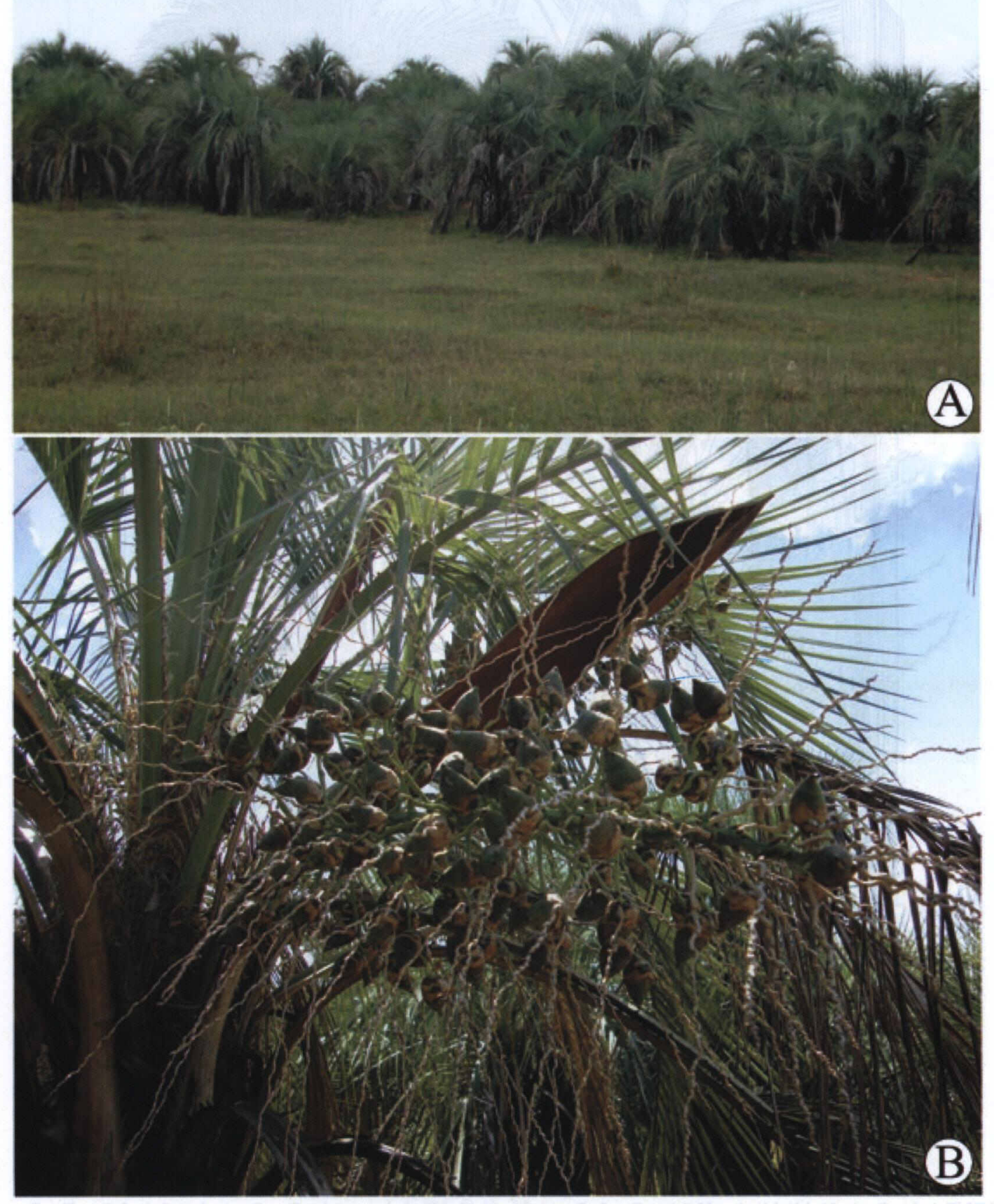

FIGURA 7 - Butia Noblickii. A - Vista panorâmica do palmar de Paso de los Libres (Corrientes, Argentina). B - Bráctea peduncular e infrutescência (cacho). 


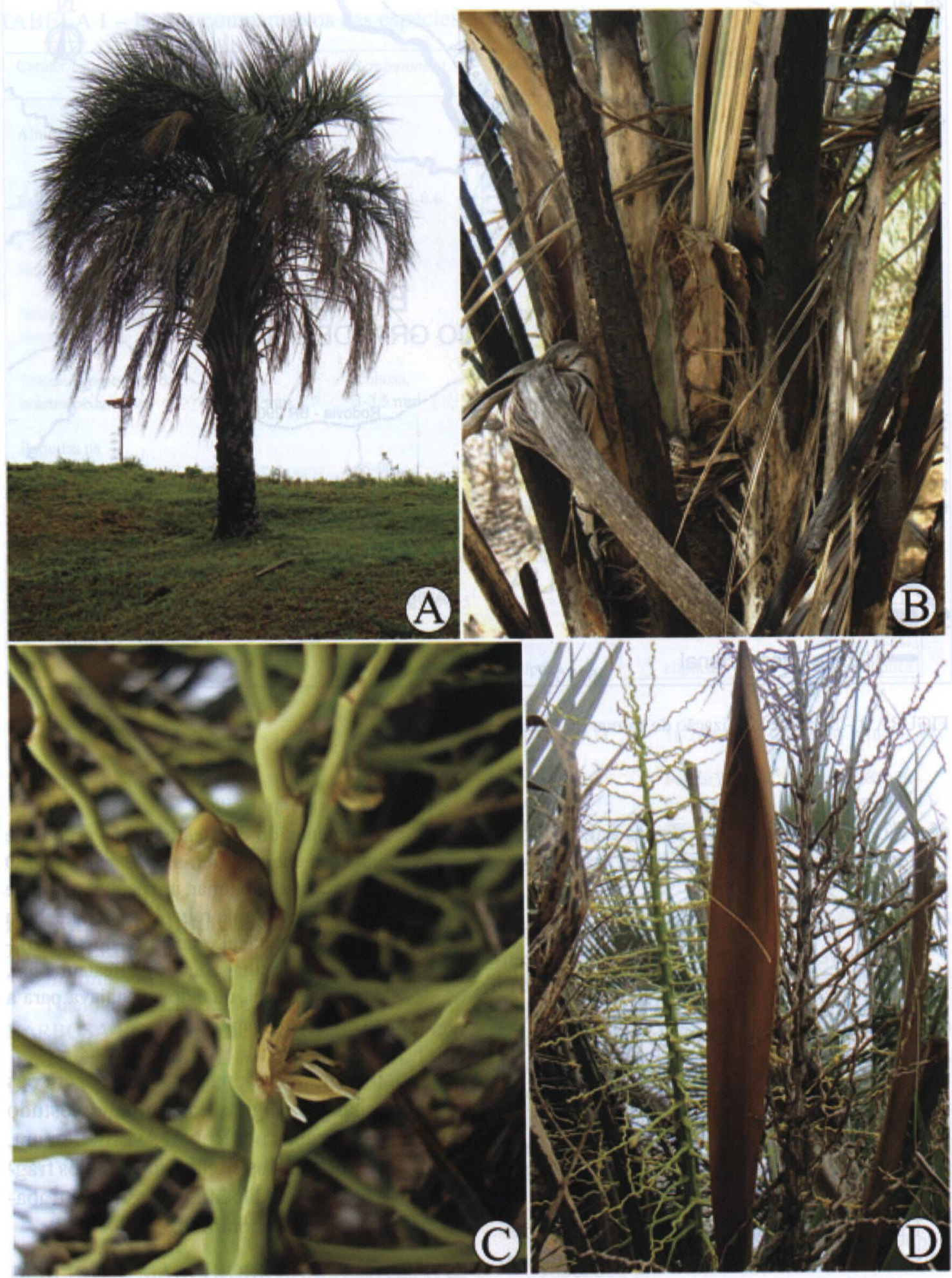

FIGURA 8 - Butia Noblickii. A - Indivíduo adulto, isolado. B - Base das folhas (pecíolos) e bainhas. C - Parte basal de rachilas, com flores pistilada e estaminada. D - Detalhe de bráctea peduncular e inflorescência (cacho). 


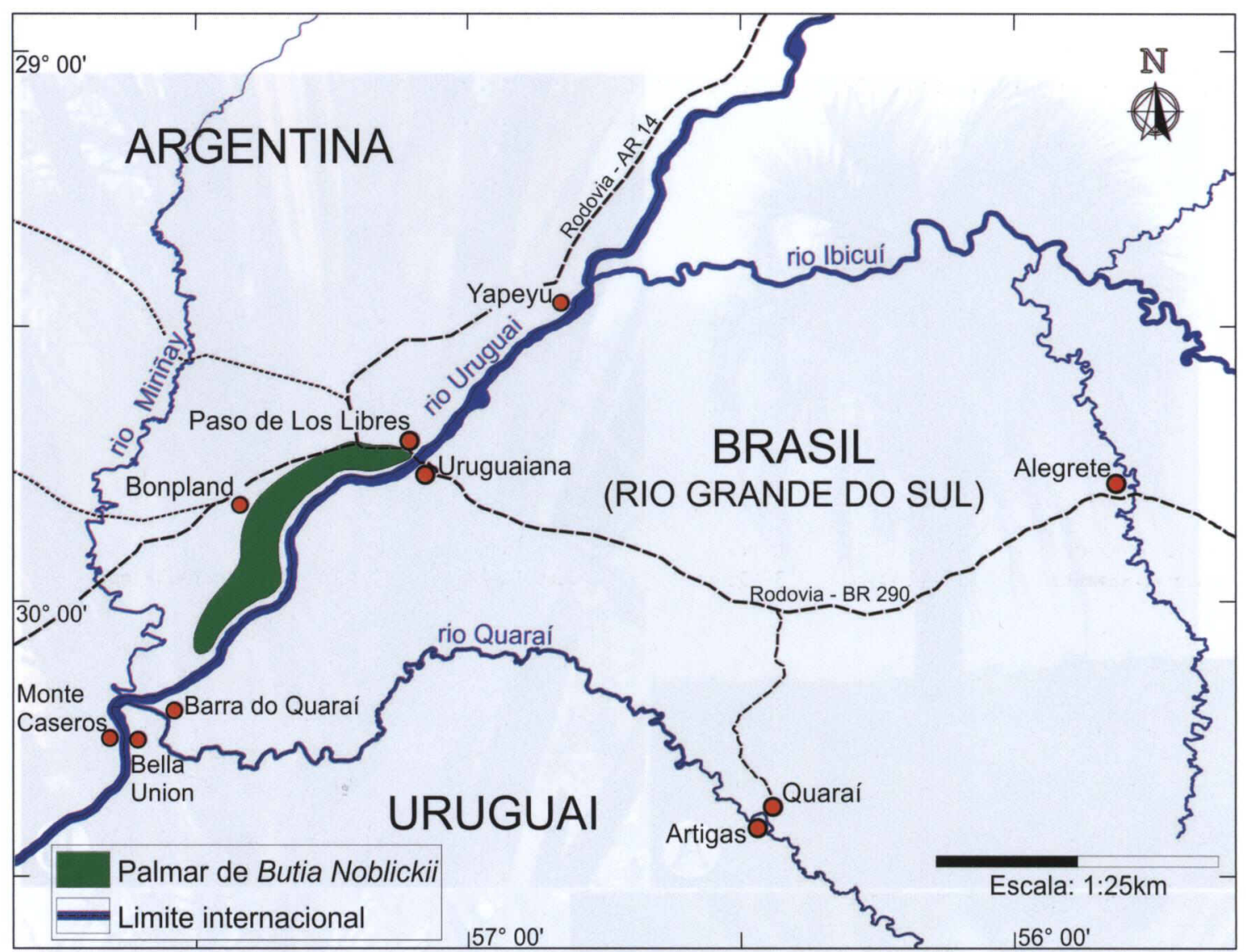

FIGURA 9 - Mapa de localização do palmar de Butia Noblickii.

cês. Ao sair da atual Paso de los Libres, AvéLallemant galopou inicialmente para oeste, rumo a

"um distante palmar, que mais belo não se pode ver. Da coxilha moderadamente ascendente, sem vestígio de mato, se elevavam livres e desembaraçados, às centenas, os esbeltos troncos e inclinavam as frondes ao vento da manhã, sem que nenhuma árvore de outra família de plantas perturbasse a impressão que produzia esse pequeno mundo de palmeiras em toda sua pureza (...). Logo adiante desse palmetum (...) começa um perfeito pampa". ${ }^{23}$

Em ligeiro resumo dos aspectos mais notáveis do "reino vegetal" encontrados em sua viagem, Avé-Lallemant volta a destacar a forte impressão causada pelo palmar de Butia Noblickii:
"Não menos do que tantos belos grupos de araucárias me atraíram alguns palmares. $\mathrm{O}$ mais encantador palmar, um pequeno bosque de palmeiras sobre a relva lisa, sem nenhum vestígio de matagal, encontrei no solo correntino, duas milhas adiante de Restauración, além do Uruguai, quando eu viajava para a casa do velho Bonpland". ${ }^{24}$

Dificilmente se poderia conseguir descrições literárias mais fidedignas do palmar em estudo do que as realizadas por Robert Avé-Lallemant, motivo pelo qual se justifica a inclusão dos fragmentos e notas de rodapé inseridos neste trabalho, de nítido cunho botânico.

\footnotetext{
${ }^{23}$ AVÉ-LALLEMANT, 1953. Op. cit., p. 282.

${ }^{24}$ AVÉ-LALLEMANT, 1953. Op. cit., p. 340.
} 
TABELA 1 - Dados comparativos das espécies do grupo Butia yatay.

\begin{tabular}{|c|c|c|c|c|c|}
\hline Caráter/espécie & B. yatay & B. missionera & B. Noblickii & B. quaraimana & B. Witedii \\
\hline Altura (m) & $8-16$ & $5-8$ & $3-6$ & $4-8$ & $4-7$ \\
\hline Estipe (m) & $6-14 \times 0.3-0.4$ & $3-6 \times 0.5-0.6$ & $2-6 \times 0.25-0.35$ & $2.5-6.5 \times 0.3-0.4$ & $3.0-6.0 \times 0.3-0.4$ \\
\hline $\begin{array}{l}\text { Comprimento das } \\
\text { folhas }(\mathrm{cm})\end{array}$ & $190-320$ & $200-300$ & $180-270$ & $150-250$ & $150-220$ \\
\hline $\begin{array}{l}\text { Número de folhas } \\
\text { contemporâneas }\end{array}$ & $16-24$ & $25-40$ & $14-24$ & $12-16$ & $14-25$ \\
\hline $\begin{array}{l}\text { Textura e espessura da } \\
\text { bráctea peduncular }\end{array}$ & $\begin{array}{l}\text { lenhosa, } \\
2.7-3.2 \mathrm{~mm}\end{array}$ & $\begin{array}{l}\text { lenhosa, } \\
\text { 3-3.5 mm }\end{array}$ & $\begin{array}{l}\text { lenhoso-papi- } \\
\text { rácea, } 1.8-2 \mathrm{~mm}\end{array}$ & $\begin{array}{l}\text { lenhosa, } \\
\text { 2.2-2.6 mm }\end{array}$ & $\begin{array}{l}\text { lenhosa, } \\
2.4-2.8 \mathrm{~mm}\end{array}$ \\
\hline $\begin{array}{l}\text { Raquilas na } \\
\text { inflorescência }\end{array}$ & $74-90$ & $65-90$ & $56-82$ & $108-152$ & $66-85$ \\
\hline Flores pistiladas (mm) & $11-13 \times 6-8$ & $11-13 \times 6-8$ & $7-9 \times 6-7$ & $11-13 \times 6-8$ & $14-20 \times 9-10$ \\
\hline Forma do fruto & ovado-turbinada & largamente ovóide & ovado-turbinada & ovado-turbinada & ovada \\
\hline Tamanho do fruto $(\mathrm{cm})$ & $4.2-5.5 \times 2.5-3.5$ & $3.5-4.5 \times 2.5-3.5$ & $3.5-4 \times 2.5-3$ & $3.5-4.5 \times 2-2.8$ & $3.6-5.6 \times 3-4.1$ \\
\hline Forma do endocarpo & $\begin{array}{l}\text { largamente } \\
\text { elíptica }\end{array}$ & $\begin{array}{l}\text { ovado a } \\
\text { largamente elíptica }\end{array}$ & elíptica & elíptica & angular-elíptica \\
\hline $\begin{array}{l}\text { Tamanho do } \\
\text { endocarpo (mm) }\end{array}$ & $24-28 \times 14-18$ & $18-22 \times 14-16$ & $18-24 \times 10-14$ & $18-22 \times 10-12$ & $28-35 \times 16-23$ \\
\hline Distribuição geográfica & $\begin{array}{l}\text { Corrientes, Entre } \\
\text { Rios (Argentina) } \\
\text { e Oeste do } \\
\text { Uruguai }\end{array}$ & $\begin{array}{l}\text { Região das } \\
\text { Missões, Rio } \\
\text { Grande do Sul }\end{array}$ & $\begin{array}{l}\text { Sudeste de } \\
\text { Corrientes } \\
\text { (Argentina) }\end{array}$ & $\begin{array}{l}\text { Palmar do } \\
\text { Coatepe, Quaraí, } \\
\text { Rio Grande do } \\
\text { Sul }\end{array}$ & $\begin{array}{l}\text { Curso médio do } \\
\text { rio Toropi, Rio } \\
\text { Grande do Sul }\end{array}$ \\
\hline
\end{tabular}

\section{REFERÊNCIAS BIBLIOGRÁFICAS}

AVÉ-LALLEMANT, R. Viagem pelo sul do Brasil no ano de 1858. Rio de Janeiro: Instituto Nacional do Livro, 1953. 398 p.

BARBOSA-RODRIGUES, J. Cocos odorata. Jardim Botânico do Rio de Janeiro 1, p. 11, t. 4A. 1891. BECCARI, O. Il genere Cocos Linn. e le palme affini. Agricoltura Coloniale, Florença, Itália, v. 10, p. 489-524, 1916.

CROVETTO, R.M.; PICCININI, B.G. La vegetación de la Republica Argentina. 1. Los palmares de Butia yatay. Revista de Invest. Agric., Buenos Aires, v. 4, n. 2, p. 153-242, 1951.

DEBLE, L.P.; MARCHIORI, J.N.C.; ALVES, F. da S.; OLIVEIRA-DEBLE, A.S. de. Survey on Butia (Becc.) Becc. (Arecaceae) from Rio
Grande do Sul state (Brazil). Balduinia, Santa Maria, n. 30, p. 21, 2011.

DEBLE, L.P.; MARCHIORI, J.N.C.; ALVES, F. da S.; OLIVEIRA DEBLE, A.S. de. Butia quaraimana (Arecaceae), uma nova espécie para o Rio Grande do Sul (Brasil). Balduinia, Santa Maria, n. 33, p. 9-20, 2012.

DOBRIZHOFFER, M. Historia de Abiponibus: Equestri, Bellicosaque Paraquariæ Natione. Viena: Typis Josephi Nob. De Kurzbek, 1784. v. 1. p. 409.

D'ORBIGNY, A.D. Voyage pittoresque dans les deux Amériques. Paris: Imprimerie de Henri Dupuy, 1836. 568 p.

D'ORBIGNY, A.D. Viaje por América meridional. Buenos Aires: Emecé, 1998. v. 1. 524 p. 
DRUDE, C. G. O. Palmae. Flora Brasiliensis, Leipzig, v. 3, parte II, p. 251-460, 1881.

ERIZE, F.; CANEVARI, M.; CANEVARI, P.; COSTA, G.; RUMBOLL, M. Los parques nacionales de la Argentinas y otras de sus áreas naturales. Buenos Aires: El Ateneo, 1993. 238 p.

IUCN. Guidelines for Using the IUCN Red List Categories and Criteria. Version 2010. 8.1. Prepared by the Standards and Petitions SubCommittee in March 2010. Available from:http:/ /intranet.iucn.org/webfiles/doc/SSC/RedList/ RedListGuidelines. (acesso 10 de novembro 2011).

KUNTZE, O. Calappa. Revisio Generum Plantarum, Leipzig, Londres, Milão, Nova York, Paris, v. 2, p. 982.1891.

LORENZI, H.; SOUZA, H.M. de; COSTA, J.T. de M.; CERQUEIRA, L.S.C. de; FERREIRA, E. Palmeiras brasileiras e exóticas cultivadas. Nova Odessa: Instituto Plantarum, 2004. 432 p.

LORENZI, H.; NOBLICK, L.R.; KAHN, F.; FERREIRA, E. Flora Brasileira. Arecaceae (Palmeiras). Nova Odessa: Instituto Plantarum, 2010. 368 p.

MARCHIORI, J.N.C.; ALVES, F. da S. O Palmar de Coatepe (Quaraí, RS): enfoque fitogeográfico. Balduinia, Santa Maria, n. 28, p. 21-26, 2011.

MARCHIORI, J.N.C.; ELESBÃO, L.E.G.; ALVAREZ FILHO, A. O Palmar de Coatepe.
Ciência \& Ambiente, Santa Maria, n. 11, p. 93104, 1995.

MARTIUS, C. F. P. de. Palmetum orbignianum. Descriptio palmarum in Paraguaria et Bolivia crescentium secundum Alc. De Orbigny exempla, schedulas et icones digessit. In: D'ORBIGNY, A. Voyage dans l'Amérique Meridionale. Paris: P. Bertrand, 1844. v. 7. p. 1-140.

MATTOS, J.R. Palmeiras do Rio Grande do Sul. Roessleria, Porto Alegre, v. 1, n. 1, p. 38-43, 1977.

REITZ, R.; KLEIN, R.M.; REIS, A. Projeto Madeira do Rio Grande do Sul. Sellowia, Itajaí, n. 3435, p. 74, 1983.

SOARES, K.; WITECK NETO, L. Ocorrência de Butia capitata e outras espécies do gênero Butia na região central do rio Grande do Sul, Brasil. In: GEYMONAT, G.; ROCHA, N. M'botiá: ecosistema único en el mundo. Castillos, Rocha, Uruguay: Casa Ambiental, 2009. p. 37-41.

SOARES, K.P; LONGHI, S.J. Uma nova espécie de Butia (Becc.) Becc. (Arecaceae) para o Rio Grande do Sul, Brasil. Ciência Florestal, Santa Maria, v. 21, n. 2, p. 203-208, 2011.

SOBRAL, M.; JARENKOW, J.A.; BRACK, P.; IRGANG, B.; LAROCCA, J.; RODRIGUES, R.S. Flora arbórea e arborescente do Rio Grande do Sul, Brasil. São Carlos: RiMA : Novo Ambiente, 2006. 350 p. 